Theme: Oxygen Steelmaking

\title{
OVERCOMING THE CONFLICT BETWEEN LONG BOF REFRACTORY LIFETIME AND EFFICIENT BOTTOM STIRRING: A CASE STUDY AT MEISHAN STEEL IN CHINA*
}

\author{
Rainer Hüsken ${ }^{1}$ \\ Patrick Pottie ${ }^{2}$ \\ Zhao Guoguang ${ }^{3}$ \\ Jürgen Cappel
}

\begin{abstract}
Over the last decades long BOF campaign lives have successfully been established due to improved quality of the refractory material and due to intensive use of slag splashing. On the other hand, steelmakers are more and more faced with elevated phosphorous contents in the hot metal. This phenomenon is a global tendency caused by the increasing pressure to utilize cheaper iron ore sources. In India, iron ore sources have traditionally elevated phosphorous contents. The phosphorous removal challenge calls for using bottom stirring at the BOF converters, as these combined technology of top oxygen blowing and inert gas stirring through the bottom, helps significantly to improve bath mixing and thus in shifting the process towards the optimum metallurgical equilibrium conditions. All this is common knowledge and daily business in the steelmaking shops all over world. Unfortunately, focusing on a long BOF refractory campaign by means of slag splashing and maintaining optimum conditions for high efficient bottom stirring are naturally conflictive aims. Applying slag splashing causes unavoidable bottom built-up which in turn covers or even blocks the bottom tuyeres. Most of the steelmaking shops today are either operating slag splashing without bottom stirring or bottom stirring without slag splashing. Some are trying slag splashing with bottom stirring but mostly only for a certain short period of the whole campaign. Baoshan Meishan Steel is an integrated steel plant, located in Nanjing (China). The plant is operating two BOF shops (3x 150t and 2x 250t), producing various steel grades. Because of the iron ore source used, the hot metal phosphorous content is rather high with up to $2,000 \mathrm{ppm}$. In order to achieve low phosphorous contents in the molten steel below 200 ppm, Meishan uses the TBM (Thyssen Bottom Metallurgy) bottom stirring technology in both of their steel plants, successfully applying slag splashing and efficient bottom stirring for campaigns up to 10,000 heats. This paper describes the operation procedures, strategies, and the maintenance concept established at Meishan Steel which is suitable to meet both conflicting targets at the same time.
\end{abstract}

Keywords: TBM combined blowing; Bottom stirring; Carbon oxygen product; Converter maintenance; Slag splashing.

1 Dipl.-Ing, Vice President, Küttner GmbH \& Co. KG, Essen, NRW, Germany; r.huesken@kuettner.com.

Eng., Sócio-Diretor, Kuttner do Brasil, Belo Horizonte, MG, Brasil; p.pottie@kuttner.com.br.

3 Eng., Head of Production and Technology Department, Shanghai Meishan Iron \& Steel Co. Steelmaking Plant, Meishan, Jiangsu Province, P.R. China.

4 Dr.-Ing., Managing Director, Cappel Stahl Consulting, Meerbusch, NRW, Germany.

* Technical contribution to the $45^{\text {th }}$ Steelmaking Seminar, May $25^{\text {th }}-28^{\text {th }}, 2014$, Porto Alegre, RS, Brazil. 


\section{INTRODUCTION}

Removal of carbon as well as phosphorous and the increase of the temperature are the basic targets of the BOF steelmaking process. In order to enhance mixing of bath and slag as the major metallurgical forces, the bottom stirring process has been developed. It injects nitrogen and argon through the bottom of the converter. A characteristic of the TBM bottom stirring process is the usage of single-hole tuyeres with an individually controlled flow rate. Simultaneously the slag splashing operation has become more and more popular in order to maximize BOF campaign life.

Applying both technologies at the same time raises a natural conflict, as slag splashing causes unavoidable bottom built-up which is negatively influencing the efficiency of bottom stirring. Most of the steelmaking shops today are either focusing on BOF campaign life and are thus operating slag splashing without bottom stirring or they are focusing on steelmaking metallurgy and are thus operating bottom stirring without slag splashing. Some BOF shops are trying the balancing act between both operating philosophies and perform slag splashing in combination with bottom stirring at the beginning of a campaign and then after a certain number of heats continue without bottom stirring for the rest of the campaign. These shops benefit at least partly from the undoubted economical savings of bottom stirring.

Meishan Steel in China is one of these BOF shops equipped with a TBM bottom stirring system from Küttner and successfully applying both philosophies simultaneously, as they are able to maintain an efficient bottom stirring during the whole BOF campaign of remarkable 10,000 heats.

The key success factor is to establish a suitable maintenance strategy and process operation procedures for the bottom stirring process.

This paper describes the operation procedures and strategies established at Meishan Steel which is daily business in balancing between the two conflicting aims.

\section{THE MODERN BOF BLOWING TECHNOLOGY}

Looking at the oxygen steelmaking installations, processes vary from "top blowing only" to "bottom blowing only" with a number of combined process types as shown in Figure 1 [1].

The most successful bottom stirring processes use single-hole tuyeres. Due to the jetting regime of the gas injected in the BOF via these tuyeres, a high turbulence and thus useful stirring energy is transferred to the melt.

Compared to the "strong" gas stirring using tuyeres, multi-hole plugs appear more as "soft" stirring or bubbling. Nevertheless also multi-hole or porous plugs achieve remarkable metallurgical effects but their weak point is that they are nonresistant to the popular slag splashing which will be discussed later in detail.

* Technical contribution to the $45^{\text {th }}$ Steelmaking Seminar, May $25^{\text {th }}-28^{\text {th }}, 2014$, Porto Alegre, RS, Brazil. 

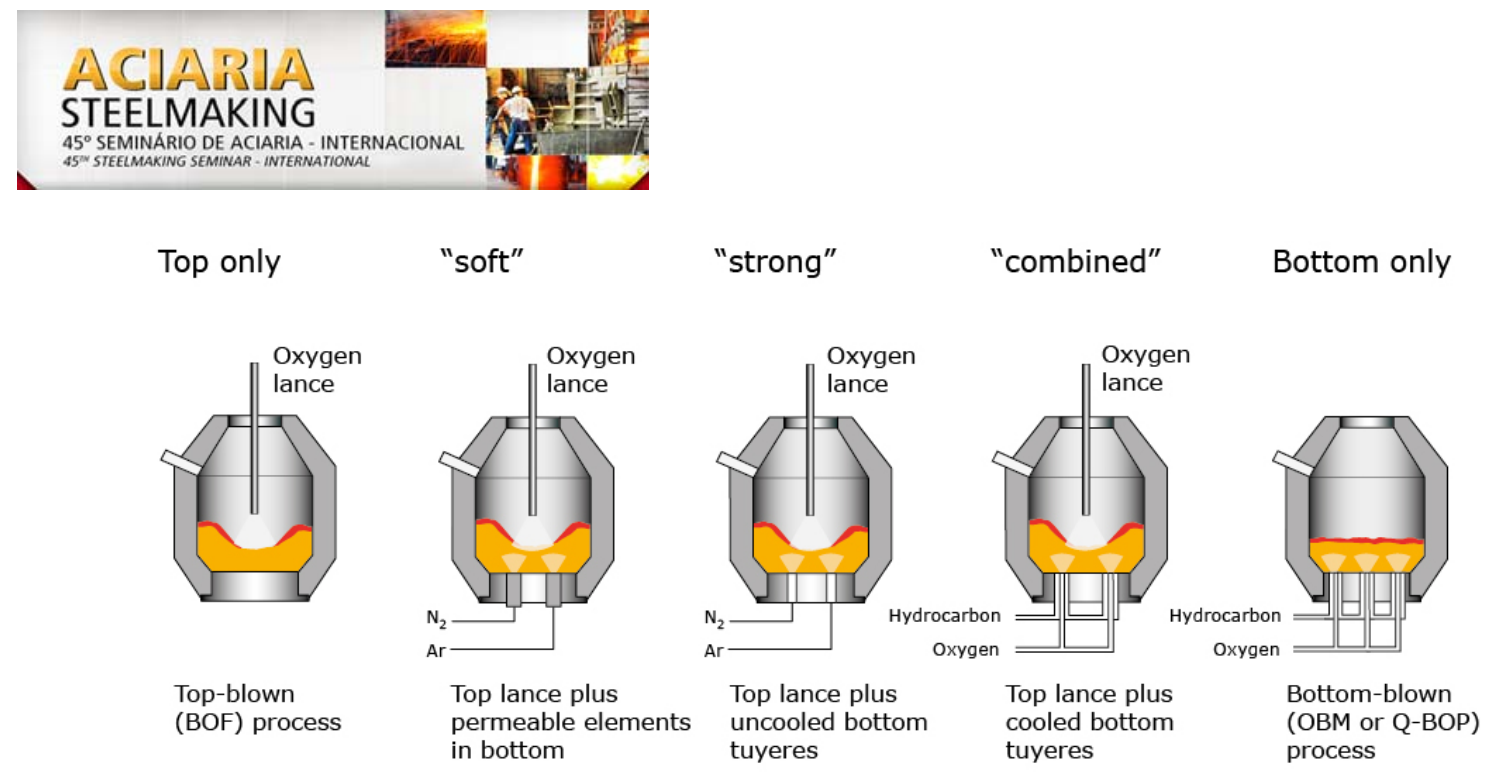

Figure 1. The Oxygen Steelmaking Process "Family" [1].

By means of bottom stirring, the mixing of the melt is enhanced and the mixing time is significantly reduced. The following typical benefits can be expected (Table 1) [2]:

Table 1. Typical benefits of bottom stirring [2]

\begin{tabular}{l|c}
\hline Parameter & Benefits of bottom stirring \\
\hline Final [C] in steel & $-0.005 \sim 0.010 \%$ \\
\hline Final [O] in steel & $-100 \sim 300 \mathrm{ppm}$ \\
\hline Final (\%T.Fe) in slag & $-2 \sim 3 \%$ \\
\hline De-Phosphorization $\mathrm{L}_{(\mathrm{P} 205)[\mathrm{P}]}$ & $+20 \sim 30$ \\
\hline Total Charge Flux & $-8 \sim 10 \%$ \\
\hline Tap-to-tap time & $-5 \sim 10 \%$ \\
\hline
\end{tabular}

It is well known that increasing the gas flow will also increase the stirring energy. But using this lever is limited as higher gas flow rates cause premature wear. Major general parameters affecting the bottom wear are [3]:

- Cooling effect of gas (flow rate through a single tuyere or plug);

- Tapping temperature;

- Quality of tuyeres/plug bricks and surrounding bricks;

- Initial thickness of the bottom and thus length of the bricks;

- Purity (oxygen content) of used stirring gases;

- Concept of bottom maintenance.

What are suitable measures to counteract bottom wear and extend the BOF campaign? Slag splashing is a proven technique to increase BOF campaigns to very high limits. After tapping, the slag in the vessel is splashed with nitrogen onto different areas of the lining during a period of $2-5 \mathrm{~min}$. Some plants prefer slag coating and slag washing. This practice retains a small amount of liquid slag in the vessel after tapping. The slag is enriched with dolomite or raw dolomite. Afterwards, the vessel is rocked several times to cover the bottom and the neighboring areas with a thin layer of slag. Hot patching and gunning are additional measures to ensure a maximum lifetime of the refractory lining [4].

Slag splashing works best with a creamy and sticky slag. But sticky slag causes the bottom of the vessel to build up with layers of slag hindering a free evolution of the gas jet from the tuyeres/plugs or even blocking them completely. This is normally not a malfunction of the bottom stirring system itself but anyhow it results in a significant deterioration of the metallurgical results due to an unfavorable distribution of the gas. Figure 2 illustrates this problem.

* Technical contribution to the $45^{\text {th }}$ Steelmaking Seminar, May $25^{\text {th }}-28^{\text {th }}, 2014$, Porto Alegre, RS, Brazil. 

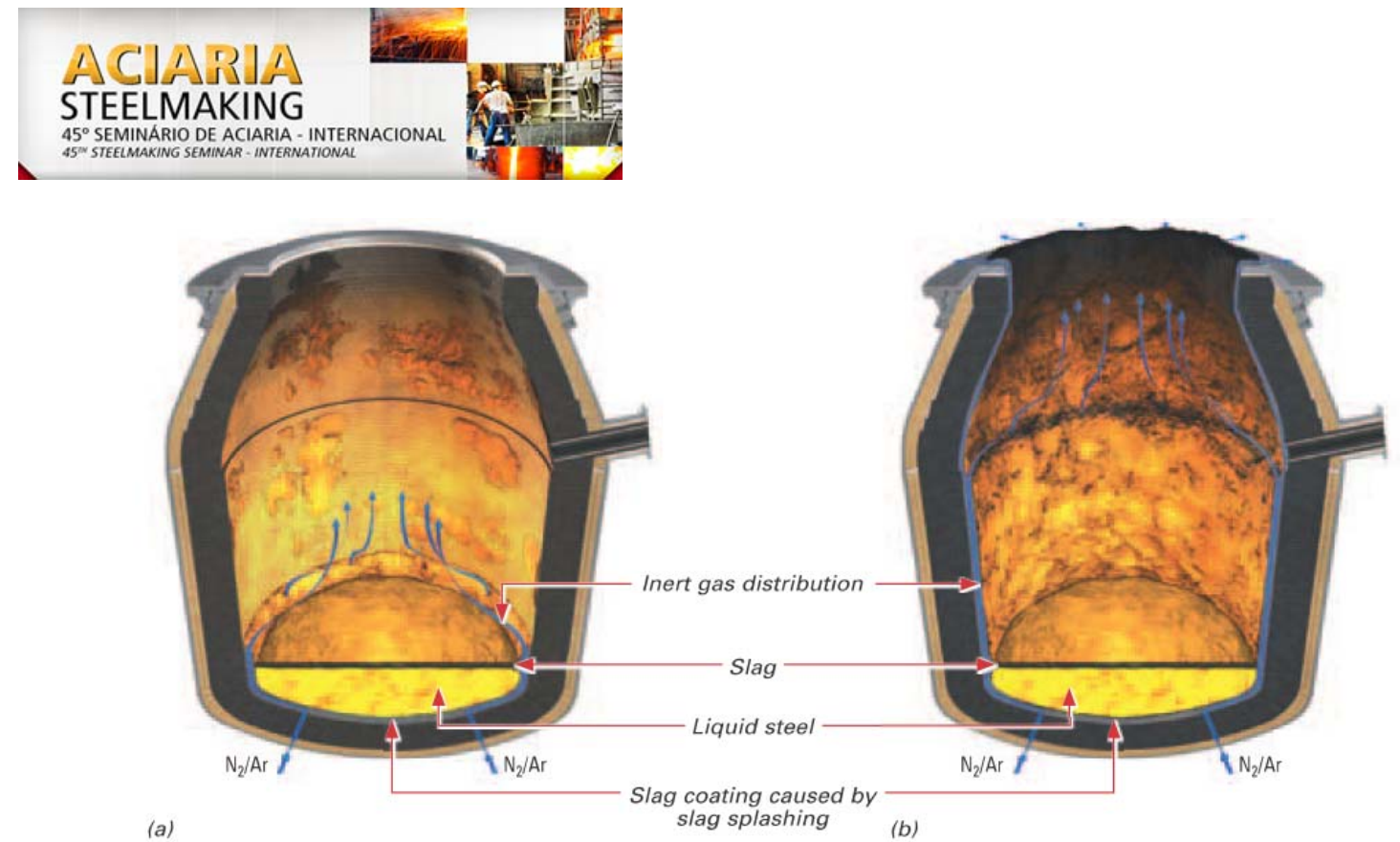

Figure 2. Bottom stirring gas distribution influenced by slag coating. (a) Thick slag layer on the bottom; and (b) Thick slag layer extending across the bottom and up the walls [4].

With a slag layer covering the bottom stirring elements, effective bottom stirring is not possible as the gas cannot be injected with a directed jet stream. It rather creeps between lining and slag layer until it finds a crack to escape. In this case the important stirring effect can no longer be fully established. With extremely thick layers of slag, the gas may even creep along the barrel to the upper cone or mouth, showing no stirring effect and no metallurgical effect at all. This phenomenon has been verified by using natural gas, identifiable by a flame. It was detected that natural gas escaped at the areas described. The left side of Figure 2 shows the situation of a slag layer just covering the bottom. The right side shows the situation with a slag layer covering bottom, lower knuckle, and barrel as created in case of intensive slag splashing [4].

It must be taken into account that in extreme cases, the inert gases neither have contact with the melt nor with the slag at all. Therefore it is essential to control the bottom thickness on a regular basis and start early countermeasure in order to maintain the function of the bottom stirring system.

\section{THE BOF SHOP OF MEISHAN}

The BOF shop \#1 of Baoshan Iron \& Steel Co. Ltd. (Meishan Steel) was commissioned in 1995 [5,6]. The annual capacity was 3.85 mtpy of continuous cast slabs in 2011. The process flow includes two hot metal torpedo car pouring stations, a three stand co-injection HM-desulphurization station, three $150 \mathrm{t}$ BOF vessels with TBM bottom stirring, three Ar-stirring stations, two ladle furnaces, two RH-degassers, one CAS station and two 2-strand slab CC-machines, see Figure 3. The quality program of the shop includes basically carbon structure steel, tin plate, pipeline steel, and some specialty steel grades.

* Technical contribution to the $45^{\text {th }}$ Steelmaking Seminar, May $25^{\text {th }}-28^{\text {th }}, 2014$, Porto Alegre, RS, Brazil. 

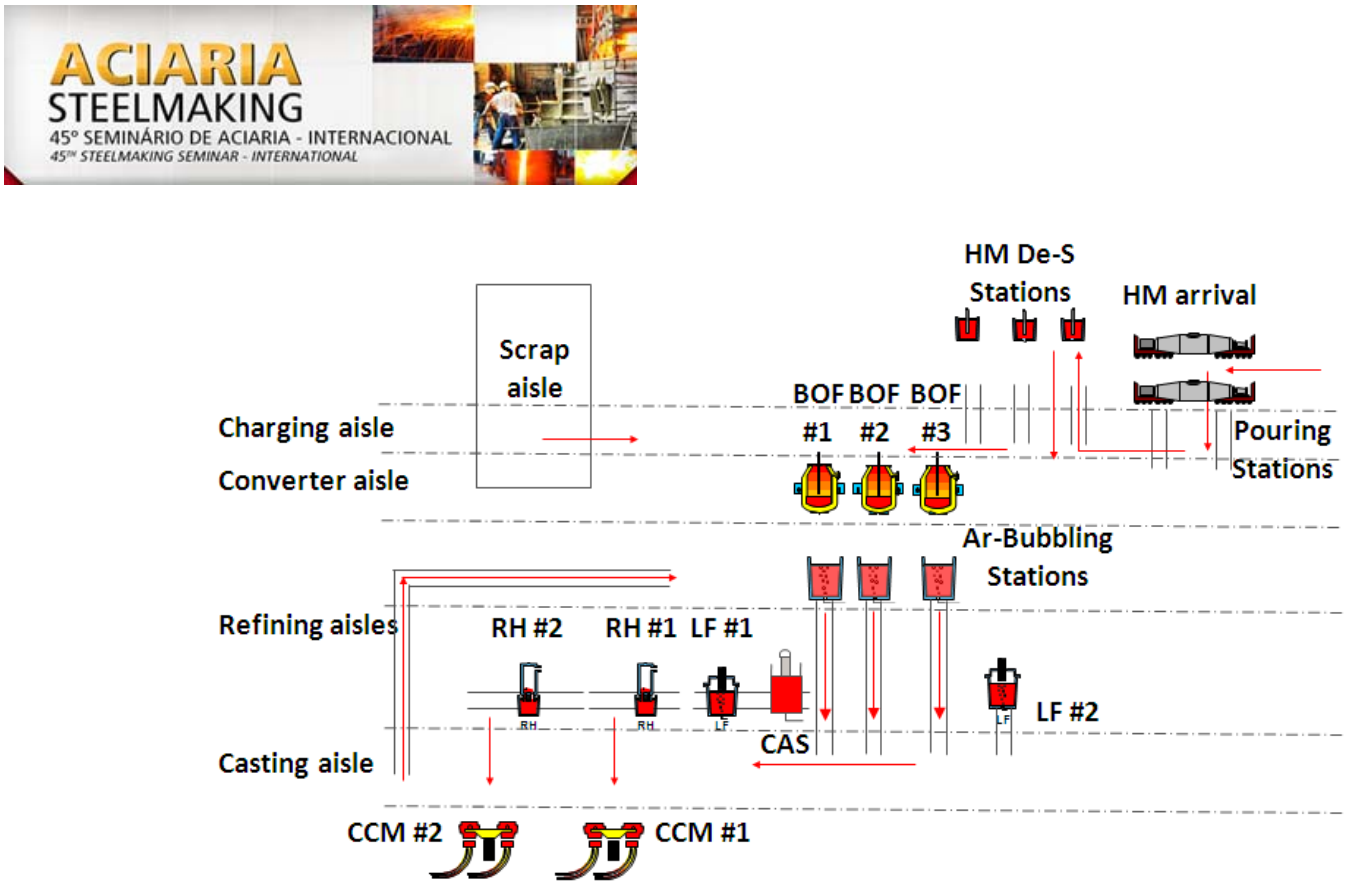

Figure 3. 150 t BOF shop \#1 at Baoshan Iron \& Steel Company (Meishan) $[5,6]$.

All three BOF converters are equipped with the TBM bottom stirring system. The inert gases used for bottom stirring are argon and nitrogen. The gas is introduced through the bottom by means of tuyeres which are installed in tuyere bricks (Figure 4). The tuyere pipes are made of special heat resistant steel.

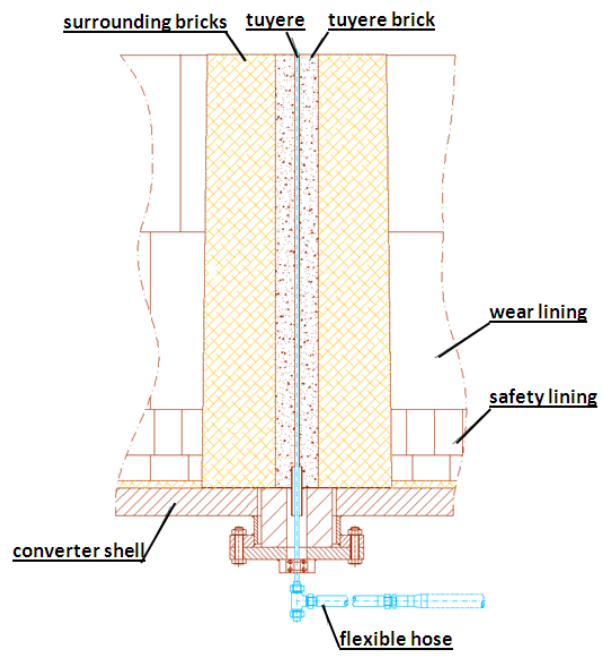

Figure 4. Design of a tuyere and its installation in the bottom of a converter at Meishan BOF steel operations.

The pipe's dimensions (inner diameter, wall thickness, and length) are calculated according to process requirements and the geometry of the converter. Typically the inner diameter is in the range of $4 \sim 6 \mathrm{~mm}$ depending on the heat size, available pressures of $\mathrm{N}_{2}$ and $\mathrm{Ar}$, min and max aimed flow rates, etc.

The flow rate of each line is controlled individually. A pattern is varying the nominal set point for the flow rate of each tuyere according to the actual process stage. In addition, the flow rate is adjusted between $80 \%$ and $100 \%$ of the nominal set point to control the individual wear of the stirring elements and their surrounding lining.

The Meishan 150t BOF vessel is equipped with 10 tuyeres in the bottom providing the inert gas from a valve station. Argon and nitrogen booster fans and storage buffers guarantee a safe and independent operation, Figure 5 . The capacity of the buffers is designed to serve for a complete heat in case of the failures in the gas supply.

* Technical contribution to the $45^{\text {th }}$ Steelmaking Seminar, May $25^{\text {th }}-28^{\text {th }}, 2014$, Porto Alegre, RS, Brazil. 

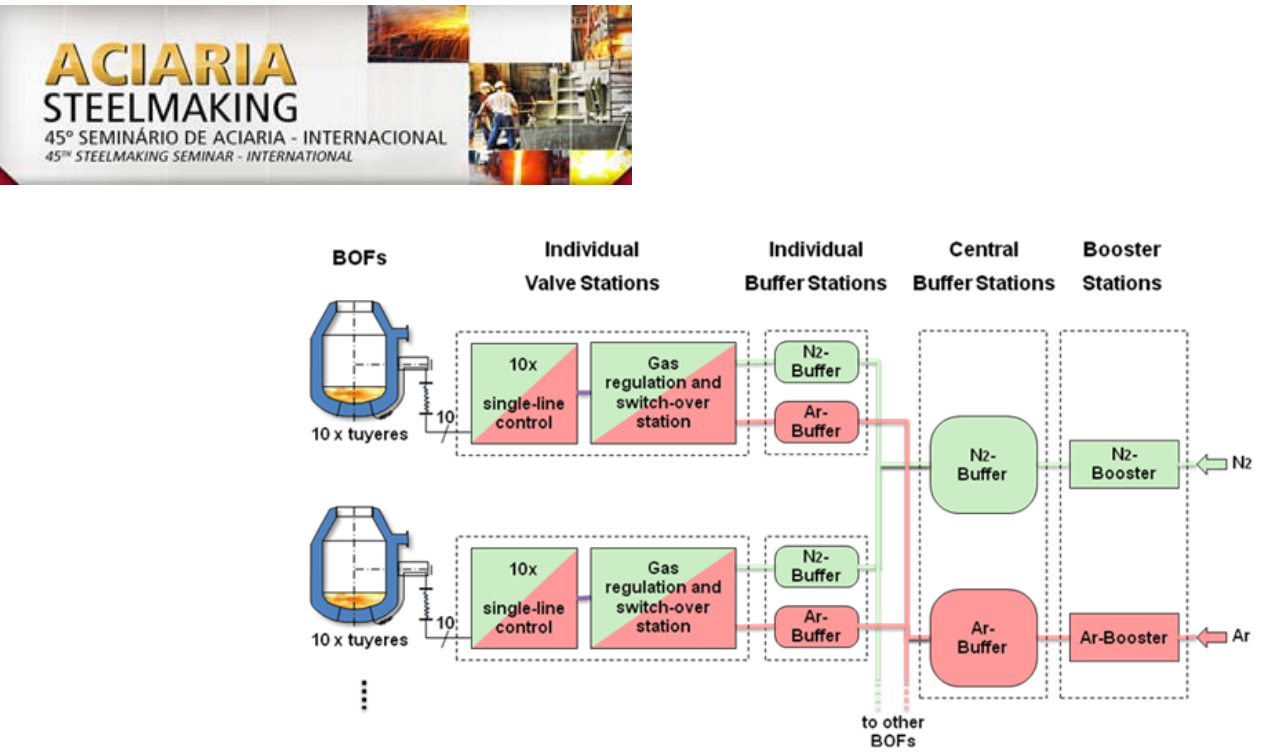

Figure 5. Bottom stirring system layout at Meishan BOF steel operations.

The minimum achievable [C][O]-product is 18. Intensive slag splashing with a ratio of more than $95 \%$ is applied in order to extend the BOF campaign life. The results achieved at Meishan Steel are exceptional for BOF converters using slag splashing as these are normally faced with detrimental built-up of the bottom (and the walls) and thus sustaining a reduction or even a total loss of the bottom stirring efficiency. Not so at Meishan, the story of Meishan is indicating new chances for improving the BOF technology and striking out an appropriate way to overcome the said conflict between optimum metallurgical results and long BOF campaign of remarkable 10,000 heats.

\section{METALLURGICAL REQUIREMENTS OF MEISHAN STEELMAKING OPERATIONS}

The metallurgical requirements to the BOF process are defined by carbon- and phosphorous contents in the final steel. The production of low and ultra-low carbon grades requires blowing down all heats to a carbon level of $0.040 \%$ in average, Figure 6 on the left side. On the other hand a too high oxidation in the BOF has to be avoided to minimize iron losses and reduce alloy and de-oxidation agent consumption $[2,7]$.
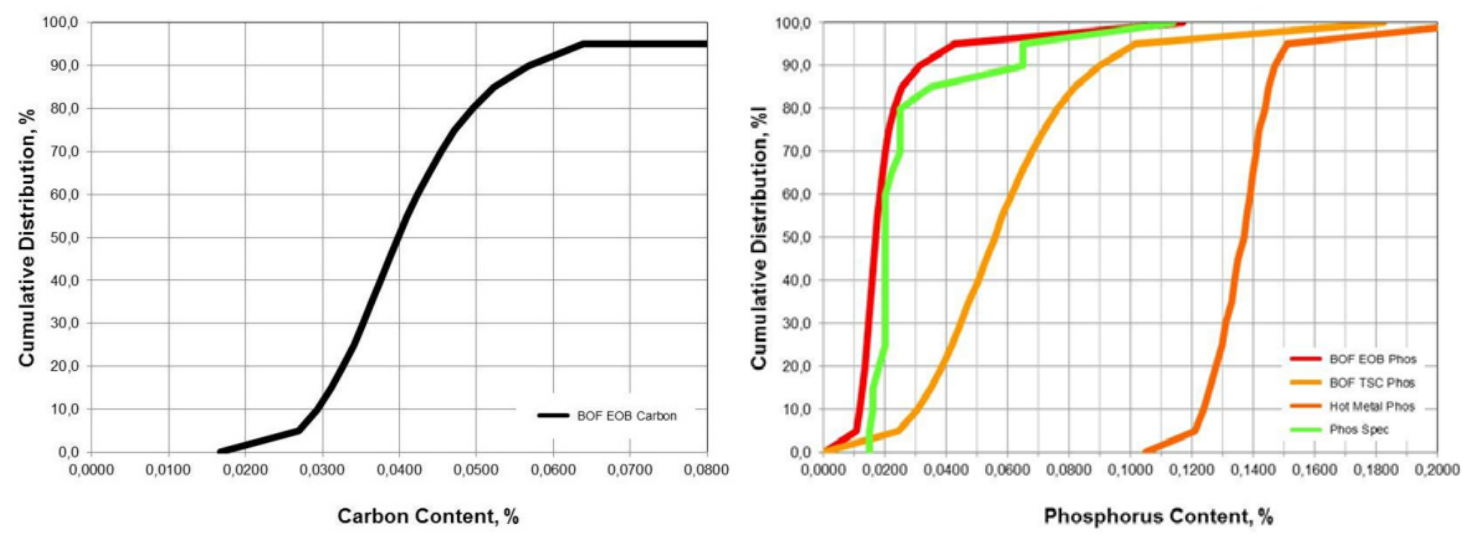

Figure 6. Carbon and Phosphorus Profile of Meishan BOF steel operations.

As this is daily business in many BOF shops, the biggest challenge for Meishan BOF operations is the hot metal phosphorus content which varies between $0.12-0.15 \%$ with an average of $0.137 \%$, as shown in Figure 6 on the right side. The phosphorus has to be blown down in the BOF process to a level $0.017 \%$ in average (red curve)

* Technical contribution to the $45^{\text {th }}$ Steelmaking Seminar, May $25^{\text {th }}-28^{\text {th }}, 2014$, Porto Alegre, RS, Brazil. 


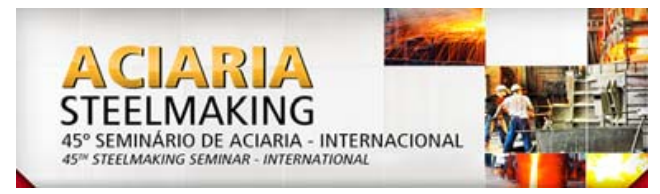

to safely meet the specification of $0.020 \%$ (green curve). One can see, that in the moment of the in-blow sampling (TSC) at approximately $1,616^{\circ} \mathrm{C}$ and $0.38 \%$ carbon, the phosphorous content is still at a level of $0.056 \%$. This means, only two minutes are remaining until the end of blow, to meet the specification. During this critical phase, an intense mixing of metal and slag is of essential importance. Bottom stirring is the most useful tool to induce that.

\section{BLOWING REGIME}

The blowing process at Meishan Steel is operated with a 5-hole lance and $15.0^{\circ}$ angle and an oxygen blowing rate of $500 \mathrm{~m}^{3}(\mathrm{STP}) / \mathrm{min}$. The heat starts with a fixed addition of $2 \mathrm{t}$ of lime into the empty furnace in order to protect the bottom against scrap impact, Figure 7. After scrap and hot metal charging, the oxygen demand is calculated and the blow is started. After successful ignition, lime, dolo lime, MgOpellets, iron ore, and BOF slurry pellets are charged. A major target is to finish all additions before $30-40 \%$ of the blow.

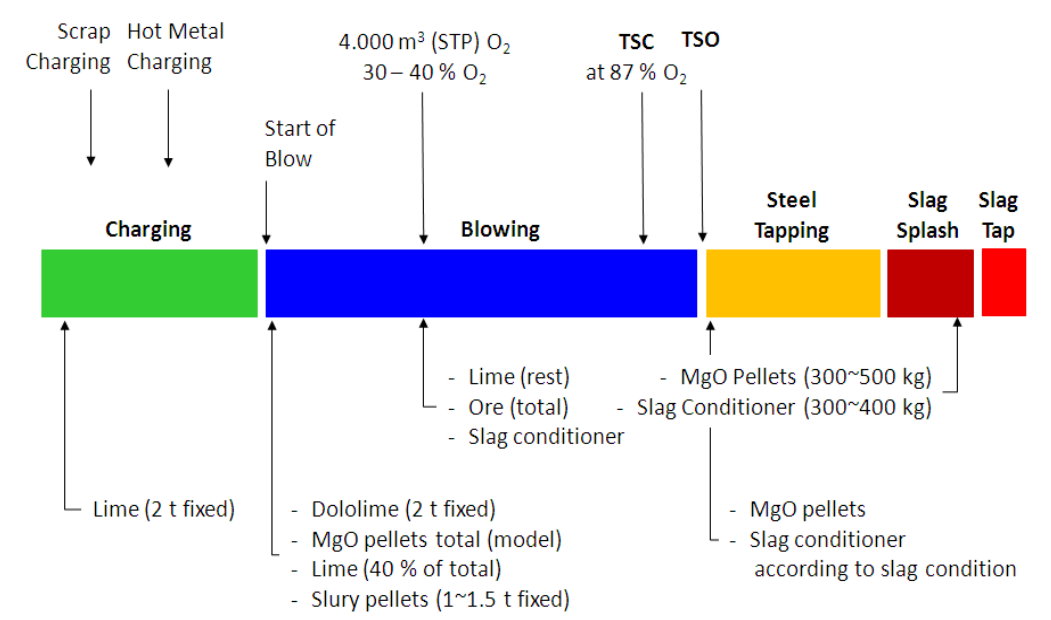

Figure 7. Blowing Regime of Meishan BOF steelmaking operations.

After $87 \%$ of the blow a TSC (temperature, steel sample) measurement with the sublance is executed. Based on the temperature result, the oxygen volume to be blown is corrected to hit the aimed blow end temperature. When the oxygen blow is finished and a post-stirring phase of $2 \mathrm{~min}$ has been elapsed, the sublance is operated for a TSO (temperature, steel sample, oxygen) measurement. After receipt of the laboratory analysis the heat is tapped. After end of tapping, the slag is partly tapped and the remaining slag is conditioned with MgO-Pellets. After a splashing period of $3-4 \mathrm{~min}$, the remaining slag is discharged to the slag pot.

\section{PROCESS RESULTS AT MEISHAN}

The metallurgical results can be evaluated by various performance indicators. The most important ones are [1,8]:

- Oxidation degree of steel [\%C][ppmO] and slag (\%TFe) contents;

- $\quad$ Phosphorus distribution factor between steel and slag $L_{P}=(\% P) /[\% P]$;

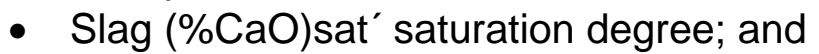

- Slag (\%MgO)sat' saturation degree.

The data was gained from operation results from April 2011 to January 2012 of the \#3 BOF representing one full campaign.

* Technical contribution to the $45^{\text {th }}$ Steelmaking Seminar, May $25^{\text {th }}-28^{\text {th }}, 2014$, Porto Alegre, RS, Brazil. 

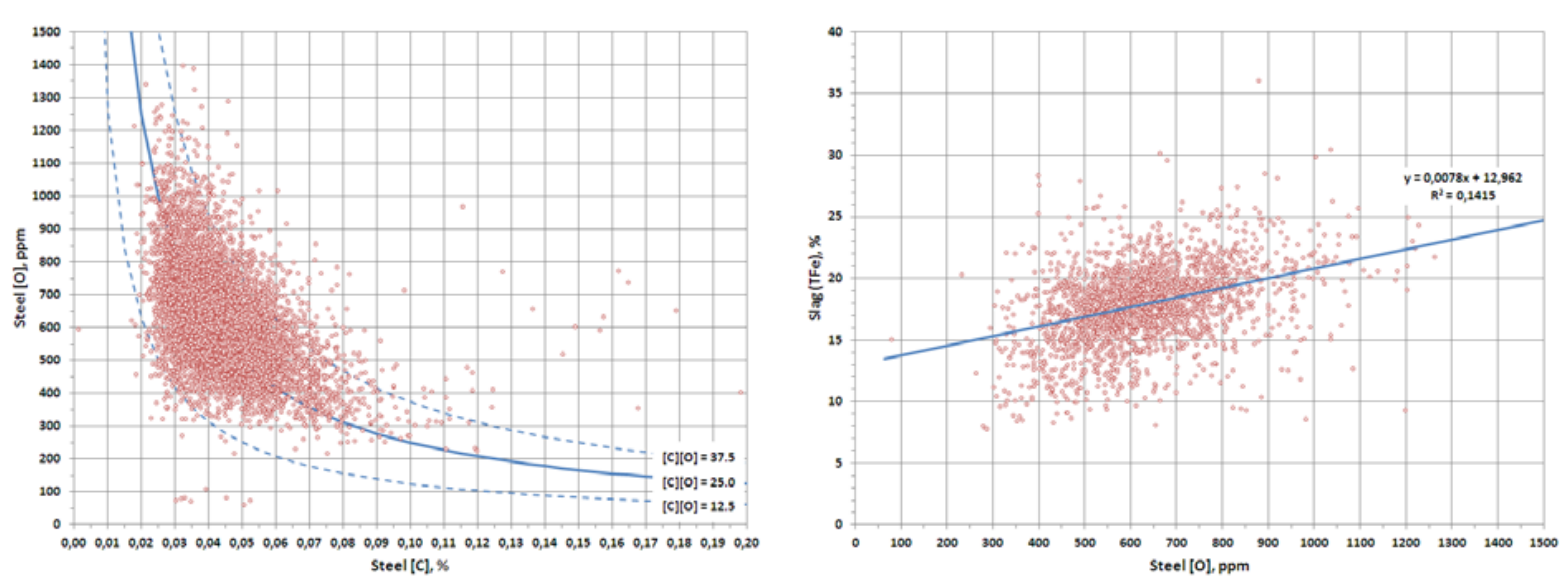

Figure 8. (a) [C][O]-product results during one campaign of \#3 BOF at Meishan Steel; (b) Slag (\%TFe) content results during one campaign of \#3 BOF at Meishan Steel.

Figure $8 \mathrm{a}$ shows the results for the $[\mathrm{C}][\mathrm{O}]$-product. The majority of the results are in the range of $12.5-37.5$ with an average [C][O]-product of 24.6 which is a normal level and valid for a temperature of $1,600^{\circ} \mathrm{C}$ and a pressure of $P_{c o}=1.0$ bar. This result ensures that for $0.040 \%$ Carbon in the liquid steel, the oxygen content will be between 400 and 800 ppm and thus limiting the consumption of de-oxidation agents during tapping and secondary refining.

Another beneficial effect of bottom stirring is the fact that the iron content in the slag (\%TFe) is reduced as shown by the tendency in Figure $8 \mathrm{~b}$. As a rule of thumb: minus $100 \mathrm{ppm}[\mathrm{O}]$ in steel results in minus 1.0\% (\%TFe) in slag. Considering a slag amount of $100 \mathrm{~kg} / \mathrm{t}$, this means an increase of steel yield of $1 \mathrm{~kg} / \mathrm{t}$.

The slag consistency parameters for effective BOF operations are the $\mathrm{CaO}$ and the $\mathrm{MgO}$ saturation degrees of the slag. Operating at the $\mathrm{CaO}$ saturation line ensures an optimum homogenous and liquid slag, lowest lime consumption, as well as lowest slag amount, Figure 9 left side. Adjusting the MgO saturation ensures a minimum $\mathrm{MgO}$ consumption from the refractory and thus an operation with lowest possible wear attack, Figure 9 right side [5,6,9-13].
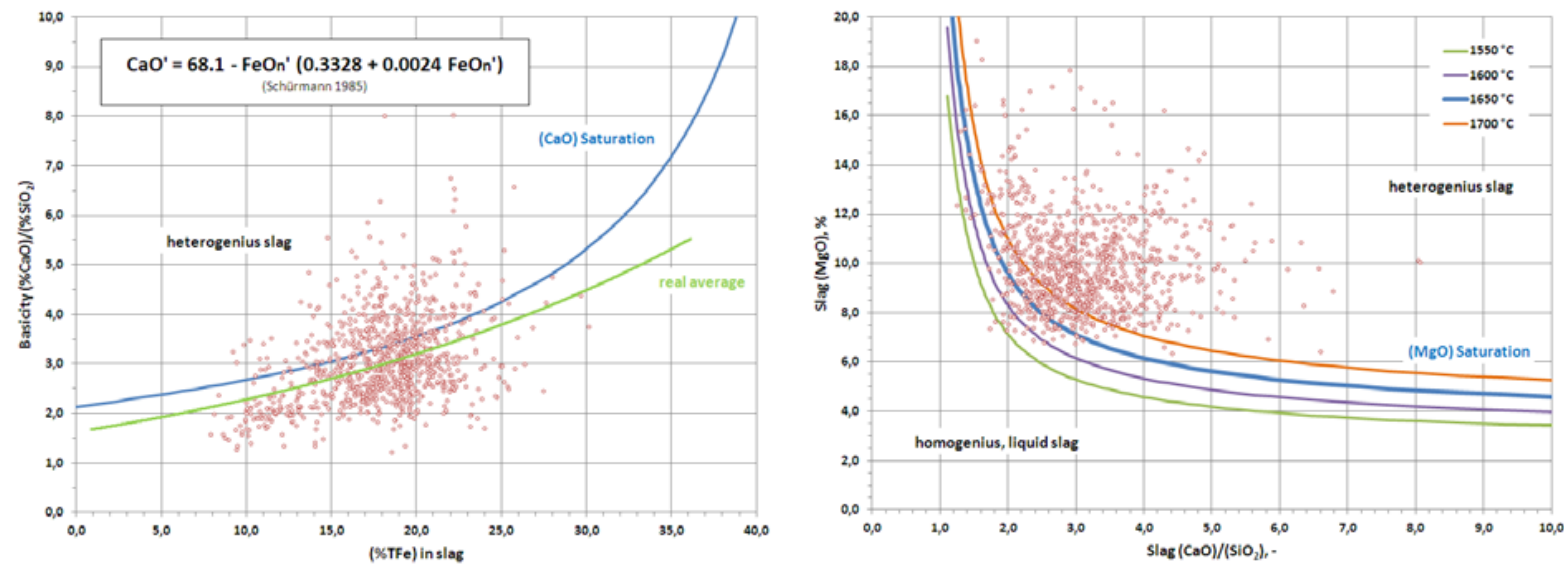

Figure 9. Slag (\%TFe) and (\%MgO) results during one campaign of \#3 BOF at Meishan.

Both parameters are wittingly controlled by Meishan. The slag basicity is increased with higher Fe-content of the slag and kept mostly below the blue saturation line. The $\mathrm{MgO}$ content varies at saturation depending on the aim steel temperature, but is also kept close to the saturation line. Therefore the slag is always reactive and liquid which ensures proper dephosphorization. The average of the phosphorus distribution

* Technical contribution to the $45^{\text {th }}$ Steelmaking Seminar, May $25^{\text {th }}-28^{\text {th }}, 2014$, Porto Alegre, RS, Brazil. 


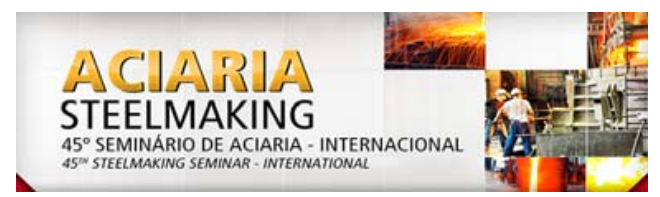

$\mathrm{L}_{\mathrm{P}}(\% \mathrm{P}) /[\mathrm{P}]$ is 70 at a temperature of $1,676^{\circ} \mathrm{C}$ and a slag (\%TFe) content of $17.9 \%$. These results are almost stable during the whole campaign which is shown in Figure 9 on the left side. The [C][O]-product and the phosphorous distribution $L_{p}$ are also plotted in form of control charts for the whole campaign. The blue lines are representing a moving average of 50 heats and show clearly the successful control of the metallurgical performance between an upper and a lower limit.
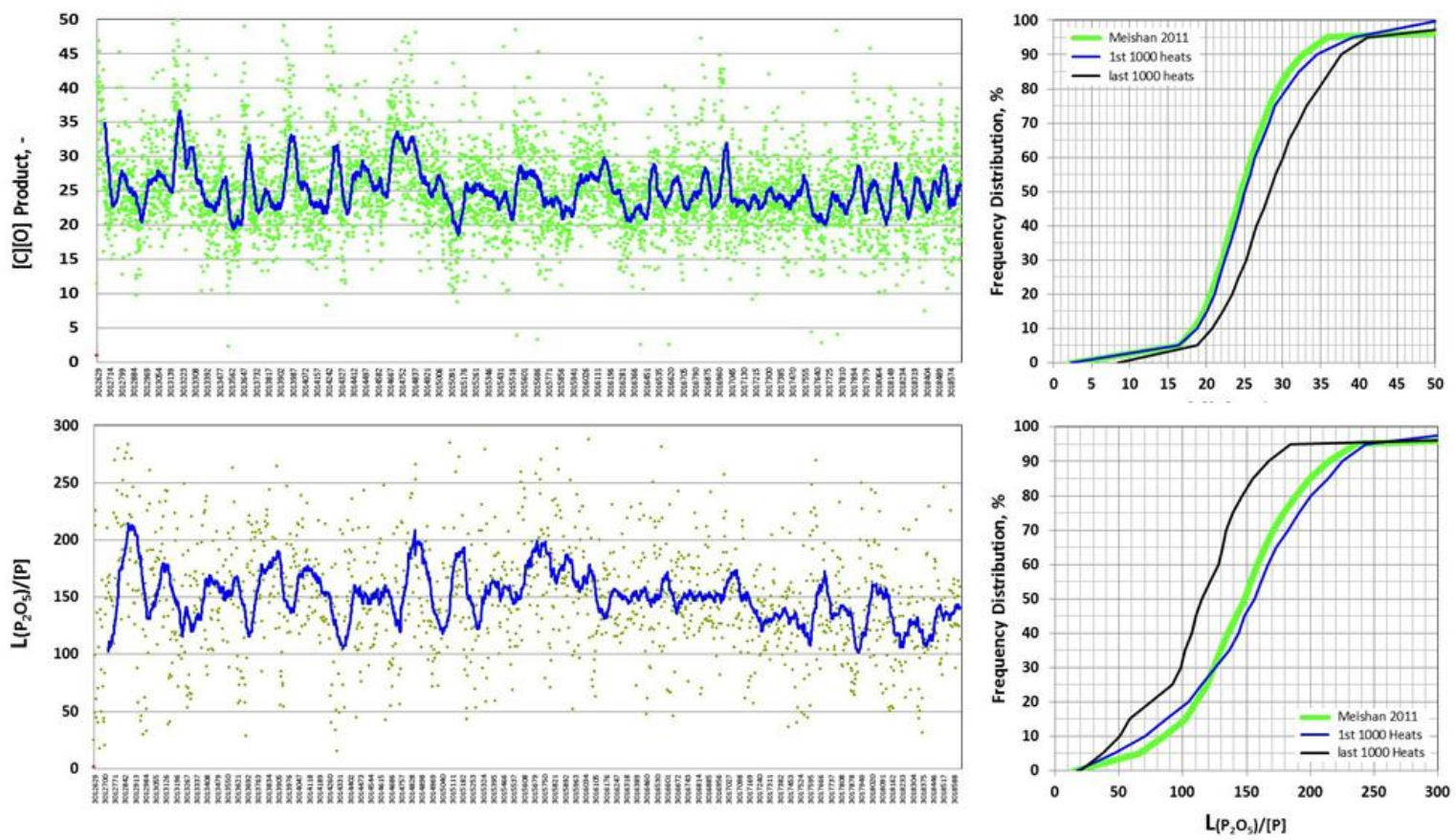

Figure 10. Metallurgical performance figures during one campaign of \#3 BOF at Meishan.

The diagrams on the right side show the accumulated frequencies of the two performance parameters. These diagrams are completed with the results of the first and the last 1,000 heats showing that there was a certain loss of metallurgical performance close to the end of the campaign (black curves: heats 9,000 to 10,000). The scattering of the results calls for an automated tracking and control of the main influencing parameters will lead to a significant reduction of the scattering and thus to an enhanced stabilization of the attainable results.

\section{MAINTENANCE OF THE CONVERTER AND THE BOTTOM STIRRING SYSTEM}

The scattering in the metallurgical results also leads to the discussion of the BOF maintenance practice. As already mentioned before, slag splashing is the key to achieve long BOF campaigns of $8,000-10,000$ heats. But only a few BOF shops are operating slag splashing and bottom stirring simultaneously with sustainable metallurgical results. So what are the key success factors at Meishan Steel to perform this way of operation successfully?

The answer is a combination of different measures. Meishan controls the bottom built-up mainly by adjusting the individual flow rate per stirring element and the slag composition.

In case of a free tuyere, the individual flow rate is reduced to $0.8 \mathrm{~m}^{3}(\mathrm{STP}) / \mathrm{min}$ (this equals $0.05 \mathrm{~m}^{3}(\mathrm{STP}) / \mathrm{min}$ per ton of steel). If a tuyere is covered with slag, the individual flow rate is increased to $1.2 \mathrm{~m}^{3}(\mathrm{STP}) / \mathrm{min}$ (this equals $0.08 \mathrm{~m}^{3}(\mathrm{STP}) / \mathrm{min}$ per ton of steel) until the tuyere has free flow again. The adjustment of the individual

* Technical contribution to the $45^{\text {th }}$ Steelmaking Seminar, May $25^{\text {th }}-28^{\text {th }}, 2014$, Porto Alegre, RS, Brazil. 
flow rates is manifested in workflow instructions and is under responsibility of the shop supervisors on a daily business basis.

In addition, the chemical composition of the slag regarding (\%MgO) and V-ratio $(\% \mathrm{CaO}) /(\% \mathrm{SiO} 2)$ is changed based on the $[\mathrm{C}][\mathrm{O}]-$ product performance results. The aim is to control the [C][O]-product in the range of $20-30$ (max. 35) as shown in Figure 10. In case of high [C][O]-product results, the slag(\%MgO) content is decreased by reducing the $\mathrm{MgO}$ pellets charge. In case the [C][O]-product is low, the slag (\%MgO) is increased by using a higher amount of MgO-pellets.

If these measures are not sufficient, the slag basicity and therefore the lime saturation index is manipulated to change the slag viscosity and to increase their capability to solute the built-up over a longer time period.

Figure 11 shows the result of laser scan measurements of the actual campaign of \#3 BOF, carried out to check the effects of slag splashing and slag composition countermeasures on the furnace lining wear. The scans are carried out on a regular base with a frequency of once per shift (approximately every 10 heats) and summarized in the figure for milestones of every 1,000 heats. It can be seen that the wear of the bottom (red line) is controlled almost constant at $8.83 \mathrm{~mm}$ per 100 heats.

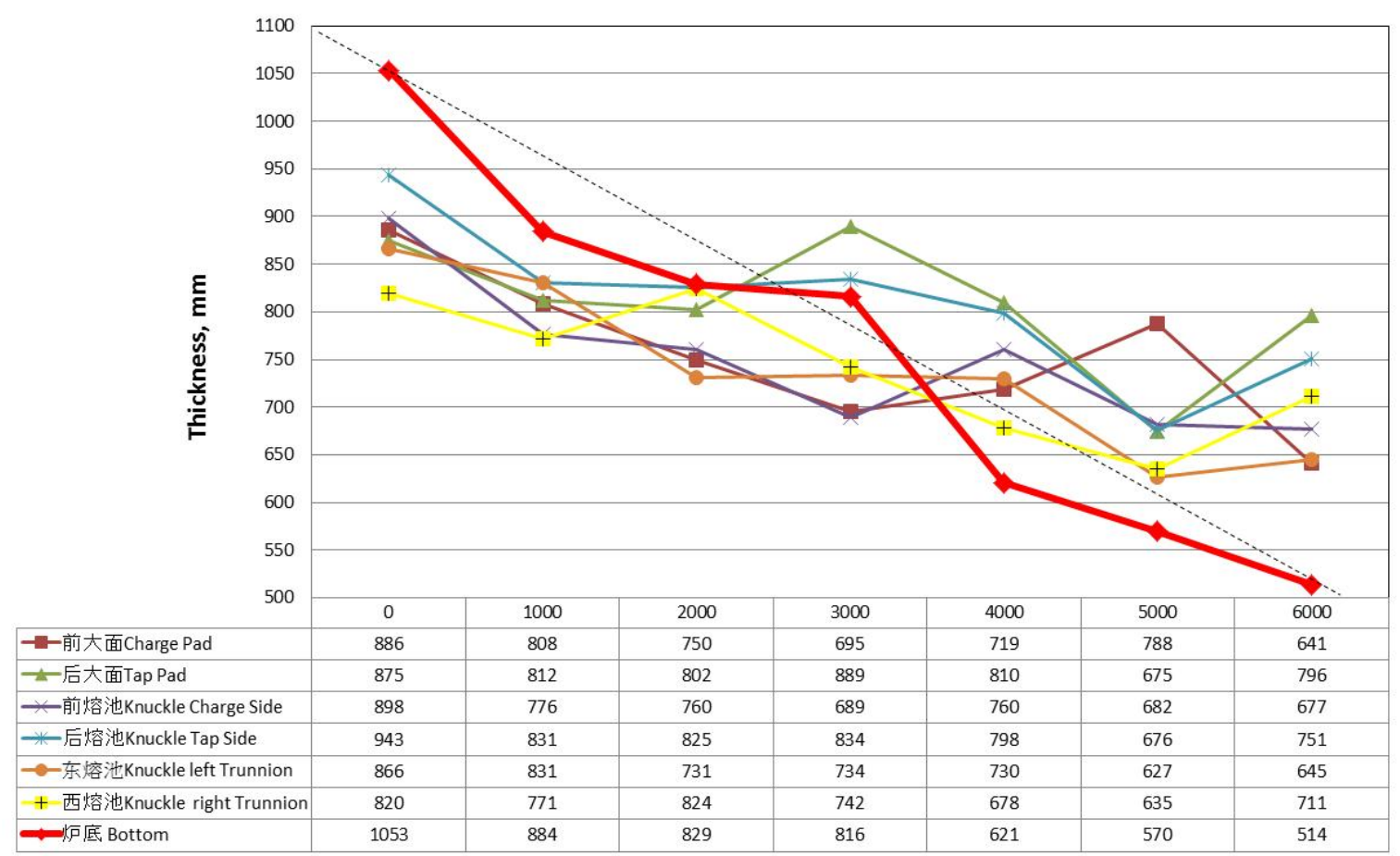

Figure 11. Wear profile development in the actual campaign of \#3 BOF at Meishan Steel.

By extrapolating this wear rate trend, a campaign of more than 9,500 heats can be predicted. Figure 12 shows a view into the \#3 BOF of Meishan at 6,000 heats. Most of the TBM tuyeres are still visible as black spots, which is due to the cooling effect of the inert gas.

* Technical contribution to the $45^{\text {th }}$ Steelmaking Seminar, May $25^{\text {th }}-28^{\text {th }}, 2014$, Porto Alegre, RS, Brazil. 

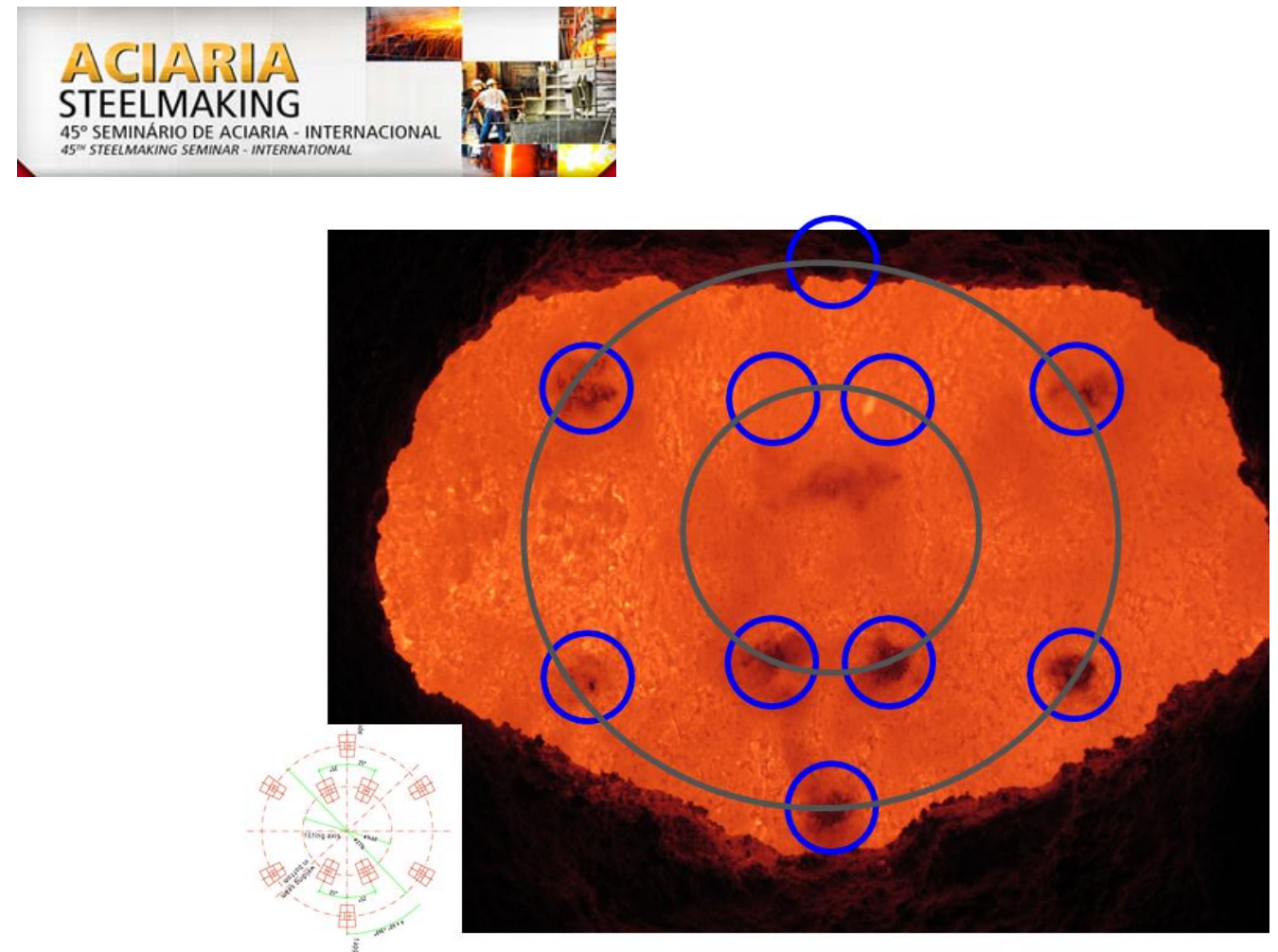

Figure 12. View into the Meishan \#3 Furnace at 6.000 heats.

\section{CONCLUSION}

Bottom stirring is a BOF technology valuable to attain metallurgical benefits such as low oxidation degree of the melt and slag, combined with low Fe-yield losses, low deoxidation agent and alloying agent consumption. The second important field of benefits from bottom stirring is the intensifying of the slag/metal reactions that is the base for efficient dephosphorization.

Slag splashing is a BOF technology valuable to achieve long lining campaigns. Throughout the last decades, steelmakers all around the world tried to combine both technologies - more or less successful. Failing was often due of a lack in controlling the slag built-up and thus losing the efficiency of the stirring elements.

This paper has presented the operation results of Baoshan Meishan Iron \& Steel Company Ltd. which is operating both technologies successfully.

Certain process strategies regarding slag manipulation and control of the bottom stirring system to stabilize the metallurgical benefits of the bottom stirring process during a whole BOF campaign have been addressed.

Key to success is a targeted manipulation of the slag composition by varying the $(\% \mathrm{MgO})$ content as well as the basicity $(\% \mathrm{CaO}) /\left(\% \mathrm{SiO}_{2}\right)$. Another critical success factor is strong stirring by means of single-hole tuyeres, which are able to withstand a certain bottom built-up unavoidable when reducing the bottom wear rate with slag splashing. Individual gas flow control of each tuyere is essentially necessary to respond to premature wear or to a beginning blockage of the tuyeres.

The results achieved at Meishan Steel are exceptional for BOF converters using slag splashing, indicating new chances for improving the BOF technology and striking out an appropriate way to overcome the said conflict between optimum metallurgical results and long BOF campaign.

Consequently Meishan relied also for their newly built 250 t BOF shop on the proven TBM technology from Küttner and started operation successfully in 2012.

* Technical contribution to the $45^{\text {th }}$ Steelmaking Seminar, May $25^{\text {th }}-28^{\text {th }}, 2014$, Porto Alegre, RS, Brazil. 


\section{REFERENCES}

1 Fruehan RJ. The making shaping and treating of steel. $11^{\text {th }}$ edition. Pittsburgh: AISI Steel Foundation;1998.

2 Winterfeld F. LD-Prozess und kombinierte Blasverfahren. Metallurgie des Eisens, chap. 2 - Stahlerzeugung. VDEh-Kontaktstudium; 52/1992.

3 Mills KC, Su Y, Fox AB, Li Z, Thackray RP, Tsai HT. A Review of Slag Splashing. ISIJ International. 2005;45(5): 619-633.

4 Kollmann T, Jandl C, Schenk J, Mizelli H, Höfer W, Viertauer A, Hiebler M. Comparison of basic oxygen furnace gas purging options. RHI Bulletin. 2012; Volume(1):8-15.

5 Zhao G, Zuo K, Guo Z. Application and maintenance of TBM combined blowing technology in Meishan converter. In: Proceedings of the 5th European Oxygen Steelmaking Conference; 26-28 June 2006; Aachen, Germany. Düsseldorf: Stahl-Institut VDEh; 2006. p.130-135.

6 Cappel J, Huesken R, Fechner R. Use of hot metal with high phosphorus content in combined blowing BOF converters. Iron \& Steel Technology; 2011; November: 46-57.

7 Krieger W. 50 Jahre LD-Prozess - 50 Jahre Innovation. BMH. 2003;148(7):247-253.

8 Chuckwulebe B, Klimushkin AV, Kuznetsov GV. The Utilization of High-[\%P]phorus Hot Metal in BOF Steelmaking. Iron \& Steel Technology. 2006;11:45-53.

9 Cappel J, Wünnenberg K. Cost-Saving operation and Optimization on Metallurgical Reactions in BOF Practice. Iron \& Steel Technology; 2008; November: 66-73.

10 Cappel J, Wünnenberg K. Kostengünstige Arbeitsweise und optimierte metallurgische Reaktionen beim Sauerstoffaufblasverfahren. Stahl und Eisen.2008;128(9):55-66.

11 Bruckhaus R, Lachmund $\mathrm{H}$. Stirring strategies to meet the highest metallurgical requirements in the BOF process. Iron \& Steel Technology. 2007;November:44-50.

12 Donayo R, et al. Decrease of fume emissions in the converter by new process for high Silicon and Phosphorus hot metal. In: $17^{\text {th }}$ IAS Steelmaking Conference; 2009; Buenos Aires, Argentina. San Nicolas: IAS; 2009.

13 Chigwedu C, Kempgen J, Pluschkell W. A new approach for the dynamic simulation of the BOF-process. Stahl \& Eisen. 2006;126(12):25-31.

* Technical contribution to the $45^{\text {th }}$ Steelmaking Seminar, May $25^{\text {th }}-28^{\text {th }}, 2014$, Porto Alegre, RS, Brazil. 